\title{
The Burden of Self-Reported Rhinitis and Associated Risk for Exacerbations with Moderate-Severe Asthma in Primary Care Patients
}

This article was published in the following Dove Press journal:

Journal of Asthma and Allergy

Vicky Kritikos, (iD ${ }^{1,2}$ David Price, (iD) ${ }^{3-5}$ Alberto Papi, (iD ${ }^{6}$ Antonio Infantino, ${ }^{7}$ Björn Ställberg, ${ }^{8}$ Dermot Ryan, (iD ${ }^{3,9}$ Federico Lavorini, (iD) ${ }^{10}$ Henry Chrystyn, " John Haughney, (iD) ${ }^{12}$ Karin Lisspers, (iD) ${ }^{8}$ Kevin GruffyddJones, (iD) 13

Miguel Román Rodríguez, (iD) 14

Svein Høegh Henrichsen, ${ }^{15}$

Thys van der Molen, (iD) ${ }^{16}$

Victoria Carter, ${ }^{3,4}$ Sinthia BosnicAnticevich (D) 1, 17,18

'Quality Use of Respiratory Medicines Group, Woolcock Institute of Medical Research, University of Sydney, Sydney, NSW, Australia; ${ }^{2}$ Department of Respiratory and Sleep Medicine, Royal Prince Alfred Hospital, Sydney, NSW, Australia;

${ }^{3}$ Optimum Patient Care, Cambridge, UK;

${ }^{4}$ Observational and Pragmatic Research Institute, Singapore, Singapore; ${ }^{5}$ Centre of Academic Primary Care, Division of Applied Health Sciences, University of Aberdeen, Aberdeen, UK;

${ }^{6}$ Respiratory Medicine, University of Ferrara, Ferrara, Italy; ${ }^{7}$ Special Interest Respiratory Area, Italian Interdisciplinary Society for Primary Care, Bari, Italy; ${ }^{8}$ Department of Public Health and Caring Sciences, Family Medicine and Preventive Medicine, Uppsala University, Uppsala, Sweden; ${ }^{9}$ Usher Institute, University of Edinburgh, Edinburgh, UK;

${ }^{10}$ Department Experimental and Clinical Medicine, University of Florence, Florence, Italy; "Inhalation Consultancy Ltd, Leeds, UK; ${ }^{12} \mathrm{NHS}$ Greater Glasgow \& Clyde R\&D, Glasgow, UK; ${ }^{13}$ Box Surgery, Box, UK; ${ }^{14}$ Primary Care Respiratory Research Unit Instituto De Investigación Sanitaria De Baleares (IdISBa), Palma, Spain; ${ }^{15}$ Department of Primary Health Care Services, Norwegian Directorate of Health, Oslo, Norway;

${ }^{16}$ Department of Primary Care, University of

Groningen, University Medical Centre Groningen,

Groningen, the Netherlands; ${ }^{17}$ Sydney Medical

School, Faculty of Medicine and Health, The

University of Sydney, Sydney, NSW, Australia;

${ }^{18}$ Central Sydney Local Area Health District,

Sydney, NSW, Australia

Correspondence: Vicky Kritikos

Woolcock Institute of Medical Research, Glebe,

Sydney, NSW, Australia

Tel +6I 402995125

Fax +61291140014

Email vicky.kritikos@sydney.edu.au
Purpose: There is a dearth of research regarding the prevalence and nature of patientreported rhinitis and its relationship with risk of asthma exacerbations. The aim of this study was to (i) determine the prevalence, severity and treatment of self-reported rhinitis symptoms among adults aged $\geq 18$ years with asthma treated at Global Initiative for Asthma (GINA) Step 3 and above and (ii) compare the demographics, clinical characteristics, medication use, side-effects and healthcare practitioner review between patients who report rhinitis symptoms and those who do not and (iii) determine whether patient-reported rhinitis is associated with risk of asthma exacerbations in the total patient sample.

Patients and Methods: This analysis used data from the iHARP (Initiative Helping Asthma in Real-life Patients) asthma review service - a cross-sectional observational study (2011 and 2014) in seven countries that captured data on patient demographics, rhinitis symptoms, asthma symptoms, indicators of exacerbations, medication use, oropharyngeal effects and side-effects, using practitioner- and patient-reported questionnaires. Comparisons between patients with and without rhinitis were tested. Univariate logistic regression was used to identify variables associated with risk of exacerbations for entry into multivariable logistic regression.

Results: This report contains data from 4274 patients: 67.4\% (2881/4274) reported rhinitis symptoms and of which $65.7 \%$ (1894/2881) had not received a doctor diagnosis; $36.5 \%$ (1052/2881) had moderate-severe rhinitis, 12.4\% (358/2881) had used intranasal corticosteroids and $19.8 \%(569 / 2881)$ oral antihistamines. Patients with coexisting moderate-severe rhinitis were more likely to have GINA-defined uncontrolled asthma than those with mild rhinitis or no rhinitis. Moderate-severe rhinitis was associated with $40 \%$ increased risk of asthma exacerbations (OR=1.40, 95\% CI: 1.02-1.90).

Conclusion: This study identified a major gap in the diagnosis and management of rhinitis in a cohort of people with asthma treated at GINA Step 3 and above who are managed in general practice. It highlights the need for practitioners to identify, evaluate and optimally treat rhinitis in adults with asthma, which is a significant factor associated with exacerbation risk.

Keywords: asthma symptom control, comorbidities, oral steroids, preventer, reliever, sideeffects

\section{Introduction}

Asthma and rhinitis are both heterogenous chronic respiratory conditions, with prevalence rates increasing worldwide. ${ }^{1,2}$ Asthma affects $\sim 30$ million people in Europe $^{1}$ and over 5 million people in the United Kingdom, ${ }^{3}$ with allergic rhinitis 
(AR), the most common form of non-infectious rhinitis, affecting up to $32 \%$ of people in Europe and $29 \%$ of people in the United Kingdom. ${ }^{2,4}$ If uncontrolled, AR has a substantial negative impact on peoples' lives, imposing a high socioeconomic and health burden on individuals and society. ${ }^{5-9}$ Asthma and AR frequently coexist, ${ }^{10}$ with up to $80 \%$ of asthma patients having AR and over $40 \%$ of AR patients having asthma. ${ }^{11}$ The links between asthma and AR have been well characterised, ${ }^{12}$ and can be regarded as manifestations of a single syndrome in two contiguous parts of the respiratory tract. ${ }^{10}$ Both diseases share similar triggers and pathophysiology. ${ }^{4} \mathrm{AR}$ usually precedes asthma and is an independent risk factor for the subsequent development of asthma. ${ }^{13-15}$

Beyond the symptomatic burden of uncontrolled rhinitis in asthma patients, significant uncontrolled rhinitis is a major trigger of asthma symptoms ${ }^{16}$ and predictor of poor asthma control, ${ }^{17-21}$ which in turn is a risk factor for exacerbations, ${ }^{16}$ thereby further compounding its impact and socioeconomic burden. ${ }^{18-24}$ In patients with asthma across various healthcare settings, the presence of uncontrolled rhinitis is associated with reduced asthma-related quality of life (QOL) ${ }^{18-22}$ and productivity, ${ }^{23}$ more physical limitations ${ }^{21,22}$ asthma medication use, ${ }^{20,23,24}$ increased rate of asthma-related general practitioner visits, ${ }^{23-25}$ absences from work, ${ }^{23}$ emergency department visits ${ }^{24,25}$ and hospitalisations ${ }^{24}$ compared to those without rhinitis. Furthermore, asthma patients with more severe rhinitis have worse asthma control than those with mild disease, ${ }^{17}$ and an elevated risk of hospital readmission due to asthma. ${ }^{26}$

The Allergic Rhinitis and its Impact on Asthma (ARIA) guidelines highlight the importance of the link between asthma and AR, and suggest that patients with asthma are assessed for AR, and vice versa, so that management of symptoms can be optimised. ${ }^{4}$ Despite a global strategy for asthma management ${ }^{16}$ and evidence-based guidelines for AR management, ${ }^{4}$ recommendations are not fully applied in clinical practice. ${ }^{27-29}$ From the physician's perspective, establishing a diagnosis of $\mathrm{AR}$ is becoming more demanding, ${ }^{12}$, and AR management is often difficult due to polysensitisation, ${ }^{30}$ the presence of both allergic and non-allergic disease elements (ie, mixed rhinitis) $)^{31}$ and entangling by phenotypes such as severe chronic upper airways disease. ${ }^{32}$ From the patient's perspective, AR symptoms are often trivialised, ${ }^{33,34}$ and management is less than ideal due to the high level of selfdiagnosis, self-selection of medication, and subsequent suboptimal or inappropriate self-management of rhinitis.${ }^{34-38}$ This has far-reaching ramifications for patients with asthma, and adds to the need of ensuring that these individuals are identified, diagnosed and treated appropriately. While patients are known to trivialise AR symptoms, it appears that healthcare professionals (HCPs) might also trivialise and under-recognise this condition in patients with poorly controlled asthma, which may lead to untreated rhinitis and overtreatment of asthma; $;$,37-40 thus, highlighting the importance of this study in primary care where most asthma in managed.

This study was developed in order to provide more data on the burden of rhinitis in asthma patients seen in general practice as there is a dearth of research regarding the prevalence and nature of patient-reported rhinitis and its relationship with the risk of exacerbations. We hypothesised that the majority of self-reported rhinitis among primary care patients with a doctor diagnosis of asthma is undiagnosed as previously described, ${ }^{39,40}$ and that significant rhinitis is associated with risk of asthma exacerbations. This research aimed to use the iHARP (initiative Helping Asthma in Real-life Patients) database ${ }^{41}$ to achieve the study objectives which were to (i) determine the prevalence, severity and treatment of self-reported rhinitis symptoms among adults aged $\geq 18$ years with asthma treated at Global Initiative for Asthma (GINA) Step 3 and above and (ii) compare the demographics, clinical characteristics, medication-taking behaviours and HCP review by between patients who report rhinitis symptoms and those who do not and (iii) determine whether patient-reported rhinitis is associated with risk of asthma exacerbations in the total sample.

\section{Methods}

\section{Data Source}

This research used the iHARP database, an international database containing anonymised patient data obtained from practices receiving the iHARP asthma review service. $^{41}$ Data were collected prospectively between June 2011 until December 2014 from enrolled primary care practices in Australia and 7 European countries (United Kingdom (UK), Italy, Spain, France, the Netherlands, Norway and Sweden).

Ethics approval for this asthma review service was acquired from each participating site according to country-specific requirements. In the UK, data were collected as part of quality improvement and became part of the 
clinical record, whereas participants in all other countries provided signed informed consent. This cross-sectional observational study was registered with the European Network of Centres for Pharmacoepidemiology and Pharmacovigilance (ENCEPP) (as ENCePP/SDPP/9651).

\section{Inclusion and Exclusion Criteria}

Patients had to meet the following inclusion criteria for the asthma review service: they had to be 16 years and older, have a current diagnosis of asthma and were prescribed at least 12 months of fixed-dose combination inhaled corticosteroid and long-acting beta 2 agonist therapy (ie, two prescriptions of GINA Step 3 or above therapy) in the year before the review. Patients were excluded if they had a diagnosis of any other chronic respiratory disease other than asthma, or they had received oral corticosteroids and/ or antibiotics for a lower respiratory condition in the 2 weeks before the review, or they had received maintenance systemic therapy for asthma. These exclusions were specified to minimise confounding on disease stability and control by additional treatments. The study cohort from the iHARP database for the current analysis was limited to adult patients ( $\geq 18$ years old) who were from practices in the above 7 European countries.

\section{Study Data and Assessments}

In the iHARP asthma review, comprehensive information about patients' demographics, asthma symptoms, rhinitis symptoms, inhaler technique, medication use, side-effects, occurrence of exacerbations and HCP review were collected using practitioner-led and questionnaire-led assessments. The questionnaire that was used is available in publications listed on the iHARP website ${ }^{41}$ and included the following sections:

Rhinitis symptoms were assessed using a single question based on the ARIA and International Primary Care Respiratory Group definition of rhinitis; ${ }^{4,42}$ 'Do you have any of these symptoms: itchy, runny, blocked nose or sneezing when you don"t have a cold?', with responses ranging from, 0 ("no"), 1 ("occasionally and little bother"), 2"occasionally but quite a bother"), 3 ("most days but little bother"), or 4 ("most days and a lot of bother"). Patients were classified as having mild rhinitis if their responses were ' 1 ' or ' 3 ' and as having moderatesevere rhinitis if their responses were ' 2 ' or ' 4 '. Patientreported intranasal corticosteroid (INCS) and/or oral antihistamine use for the treatment of rhinitis in the past year were also recorded.
The GINA criteria at the time were used to assess the level of asthma control during the week before the review visit. ${ }^{43}$ Patients were asked if they experienced: daytime symptoms (more than twice/week); any night wakening due to asthma; need for short-acting $\beta$-agonist (SABA) reliever (more than twice/week) and any limitation in daytime activity. The level of asthma control was defined as controlled (none of the above), as partially controlled (1 or 2 of the above) or as uncontrolled ( 3 or 4 of the above). Patients were also asked to rate their level of asthma control in response to the question; "In the past 4 weeks, did you believe that your asthma was "well controlled'?" with "yes" or "no" response options.

Adherence to asthma preventer therapy was assessed with a single question from the REALISE (Recognise Asthma and Link to Symptoms and Experience) study, ${ }^{44,45}$ asking patients to choose a statement that best described how they take their preventer asthma medication. Patients were also asked to indicate the highest number of puffs of SABA reliever taken in one day during the previous 4 weeks with ' $0-4$ ' or " $5-12$ or more" response options.

Patients were asked whether their inhaler technique had been checked by a HCP in the past year and whether they had seen a respiratory specialist for asthma outside the practice with response options "in the previous year", "more than a year ago" or "never". Patient-reported oropharyngeal effects while inhaling preventer treatment (ie, feeling a sensation at the back of the throat, a need to cough and/or of medication being deposited at the back of the throat) and side-effects from preventer asthma medication (ie, continual sore mouth/throat, oral thrush, bruising, hoarse voice, cough and abnormal weight gain) were recorded during the review.

Patients reported whether they had experienced any asthma exacerbations in the previous 12 months before the review visit. Exacerbations were identified by one of the following events: (a) hospital admission with breathing or chest problems; (b) emergency department (ED) visit due to asthma; or (c) a short burst (5-10 days) of oral corticosteroids for worsening asthma. The total number of exacerbations in the previous year (ie, $a+b+c)$ were calculated for each patient; a total score of zero $=$ no risk of exacerbations, and a total score $\geq 1=$ yes risk of exacerbations.

\section{Data Analysis}

Statistical analyses were performed using SPSS (IBM ${ }^{\circledR}$ SPSS $^{\circledR}$ Statistics) Version 24. There were two parts to the statistical analysis plan: 
Part 1: Descriptive statistics were used to summarise sample characteristics. Demographics, clinical characteristics, behaviours regarding medication use and review by HCPs of patients who reported rhinitis symptoms were compared to those that did not. Normally distributed continuous variables such as age were compared using Student's $t$-test, and for categorical variables such as gender and smoking status the Pearson chi-square test was used.

Part 2: An exploratory analysis was performed to identify variables associated with risk of exacerbations among the total patient sample using univariable logistic regression models, where the risk of exacerbations (no/ yes) was the dependent variable and patient demographics, clinical characteristics, behaviours regarding medication use and HCP review were the predictor variables. Tolerance values were used to test for intercorrelations among predictor variables, and those with high intercorrelations were not included for further analysis. Predictor variables that were significantly associated with risk of exacerbations were then entered into a multivariable logistic regression to predict the risk of exacerbations using a threshold for entry into the model of $\mathrm{p}<$ 0.05 and interactions between covariates were tested. The goodness of fit of the logistic regression model was confirmed by the Hosmer and Lemeshow test. A twotailed significance level of 0.05 was used for all statistical procedures.

A sample size of at least 818 participants was needed for the multiple regression analysis based on a candidate set of 10 independent variables, a small effect size $\left(0.02 f^{2}\right)$ with $80 \%$ power and a probability level of 0.05 .

\section{Results}

\section{Patient Cohort}

There were 4274 adults aged $\geq 18$ years with asthma in the iHARP database who had their asthma reviewed between June 2011 and December 2014 and all were included in the analysis. The study cohort included 2574 $(60.2 \%)$ from the UK, $652 \quad(15.3 \%)$ from the Netherlands, 527 (12.3\%) from Spain, 403 (9.4\%) from Italy, $62(1.5 \%)$ from Sweden, $36(0.8 \%)$ from Norway and $20(0.5 \%)$ from France. Table 1 shows patient characteristics: mean (SD) age of patients 50.9 (14.3) years; $60.8 \%$ female; $33.1 \%$ obese (body mass index $\geq 30 \mathrm{~kg} / \mathrm{m}^{2}$ ); $12.9 \%$ current smokers and $30.3 \%$ had GINA-defined controlled asthma.

\section{Prevalence and Severity of Coexisting Rhinitis Symptoms and Treatment}

Overall, 2881/4274 (67.4\%) patients reported rhinitis symptoms; however, of those reporting rhinitis symptoms only $34.3 \%(987 / 2881)$ had a doctor diagnosis of rhinitis (Table 1), ie, 65.7\% (1894/2881) of patients reporting rhinitis had not received a doctor diagnosis (Figure 1). Of patients reporting rhinitis symptoms, $63.5 \%(1829 / 2881)$ were classified as having mild rhinitis and $36.5 \%(1052 / 2881)$ having moderate-severe rhinitis. In the past year, $12.4 \% \quad(358 / 2881)$ of patients indicated using intranasal corticosteroid (INCS) therapy for rhinitis and 19.8\% (569/2881) oral antihistamines.

\section{Characteristics of Patients Reporting Coexisting Rhinitis Symptoms}

Patients reporting rhinitis symptoms were significantly more likely to be younger, female, have a normal body mass index and have a positive smoking history than those who did not (Table 1). The proportion of patients with GINA-defined uncontrolled asthma was significantly higher among those who reported rhinitis symptoms than those who did not $(26.8 \%$ vs $21.0 \%, \mathrm{p}<0.001)$ (Table 1$)$; and even higher among patients with moderate-severe rhinitis than those with mild rhinitis $(31.4 \%$ vs $24.2 \%$, $\mathrm{p}<0.001$ ) (Figure 2).

In the week before the review visit, a significantly higher proportion of patients who reported rhinitis symptoms experienced asthma symptoms for $\geq 3$ days, had asthma symptoms affecting their sleep or had symptoms that interfered with daily activities than those who did not (Table 2). While there was no significant difference in frequency of SABA reliever use between the two groups, patients who reported rhinitis symptoms were significantly more likely to have taken 5-12 puffs or more of SABA reliever on at least 1 day in the previous 4 weeks than those who did not $(12.8 \%$ vs $9.5 \%, \mathrm{p}=0.002)$ (Table 2). Furthermore, compared to patients who did not report rhinitis symptoms, those who did were more likely to have experienced exacerbations requiring shortterm courses of oral steroids ( $38.8 \%$ vs $30.2 \%, p<0.001)$, have taken time off work/education $(10 \%$ vs $16.6 \%$, $\mathrm{p}<0.001)$ or visited the ED due to asthma $(9.8 \%$ vs $7.6 \%, \mathrm{p}<0.001)$ in the 12 months prior the review visit (Table 2). Patients with GINA-defined partially controlled/uncontrolled asthma who reported rhinitis were 
Table I Patient Demographics and Characteristics Overall and by Patient-Reported Rhinitis

\begin{tabular}{|c|c|c|c|c|}
\hline & \multirow[t]{2}{*}{ Overall $(N=4274)$} & \multicolumn{2}{|c|}{ Patient-Reported Rhinitis } & \multirow[t]{2}{*}{ p value* } \\
\hline & & No $(n=1393)$ & Yes $(n=288 I)$ & \\
\hline Age in years, mean (SD) & $50.7(14.3)$ & $52.3(14.0)$ & $50.0(14.4)$ & $<0.001^{\mathrm{a}}$ \\
\hline \multicolumn{5}{|l|}{ Gender, n (\%) } \\
\hline Female & $2600(60.8)$ & $809(58.1)$ & $|79|(62.2)$ & $0.01^{\mathrm{b}}$ \\
\hline Male & $1674(39.2)$ & $584(41.9)$ & $1090(37.8)$ & \\
\hline \multicolumn{5}{|l|}{ BMI $\left(\mathrm{kg} / \mathrm{m}^{2}\right)$ category, $\mathrm{n}(\%)$} \\
\hline Underweight (BMI $\leq 18.49$ ) & $56(1.3)$ & $15(1.1)$ & $41(1.4)$ & $0.00 \mathrm{I}^{\mathrm{b}}$ \\
\hline Normal (BMI I8.5-24.99) & $1293(30.3)$ & $37 \mid(26.6)$ & $922(32.0)$ & \\
\hline Overweight (BMI 25-29.99) & $1509(35.3)$ & $498(35.8)$ & $1011(35.1)$ & \\
\hline Obese (BMI $\geq 30$ ) & $1416(33.1)$ & $509(36.5)$ & $907(31.5)$ & \\
\hline \multicolumn{5}{|l|}{ Smoking history, n (\%) } \\
\hline Never smoked & $2364(55.3)$ & $808(58.0)$ & $1556(54.0)$ & $0.002^{b}$ \\
\hline Past smoker & $1357(3 \mid .8)$ & $393(28.2)$ & $964(33.5)$ & \\
\hline Current smoker & $553(12.9)$ & $192(13.8)$ & $361(12.5)$ & \\
\hline Comorbidities $^{c}, \mathrm{n}(\%)$, known & $(n=3622)$ & $(n=1273)$ & $(n=2385)$ & \\
\hline Rhinitis & $1228(33.9)$ & $24 \mid(19.5)$ & $987(4 I .4)$ & $<0.001^{b}$ \\
\hline Eczema & $696(19.2)$ & $230(18.6)$ & $466(19.5)$ & $0.2^{\mathrm{b}}$ \\
\hline GORD & $480(13.3)$ & $150(12.1)$ & $330(13.8)$ & $0.1^{\mathrm{b}}$ \\
\hline \multicolumn{5}{|l|}{ Asthma symptom control (GINA-defined) ${ }^{\mathrm{d}}, \mathrm{n}(\%)$} \\
\hline Controlled & $1296(30.3)$ & $442(31.7)$ & $854(29.6)$ & $<0.001^{\mathrm{b}}$ \\
\hline Partially controlled & $1912(44.7)$ & $658(47.3)$ & $1254(43.5)$ & \\
\hline Uncontrolled & $1066(25.0)$ & $293(21.0)$ & $773(26.9)$ & \\
\hline \multicolumn{5}{|l|}{ Perceived control ${ }^{\mathrm{e}}, \mathrm{n}(\%)$, known } \\
\hline Well controlled & $2582(60.4)$ & $905(65.0)$ & $1677(58.2)$ & $<0.001^{\mathrm{b}}$ \\
\hline Not well controlled & $1692(39.6)$ & $488(35.0)$ & $1204(4 \mid .8)$ & \\
\hline
\end{tabular}

Notes: $\mathrm{p}$ value* No rhinitis symptoms versus rhinitis symptoms. ${ }^{\mathrm{P}} \mathrm{P}$ value from independent samples $t$-test. ${ }^{\mathrm{b}} \mathrm{P}$ value from chi-square test for independence. ${ }^{\mathrm{c}}$ Doctor diagnosed comorbidities. In the 7 days before an iHARP asthma review. ${ }^{\mathrm{e}}$ In the 4 weeks before an iHARP asthma review.

Abbreviations: BMI, body mass index $\left(\mathrm{kg} / \mathrm{m}^{2}\right)$; GINA, Global Initiative for Asthma; GORD, gastroesophageal reflux disease; SD, standard deviation.

more likely to accurately perceived that their asthma was "not well controlled" than those with asthma alone ( $40.9 \%$ vs $32.7 \%, \mathrm{p}<0.001)$.

Patients who reported rhinitis were significantly less likely to take preventer inhaler every day and to have had their inhaler technique reviewed by a HCP in the past year than those who did not (Table 3); yet they were significantly more likely to experience oropharyngeal effects while inhaling preventer treatment and sideeffects from preventer asthma therapy symptoms than those who did not (Table 3). In addition, patients who reported rhinitis symptoms were significantly less likely to have seen a respiratory specialist for asthma in the past year (vs more than a year ago/never) than those who did not (Table 3).

\section{Association of Rhinitis with Risk of Asthma Exacerbations}

Results of exploratory analysis using univariable logistic regression identified moderate-severe rhinitis as one of the 10 variables significantly associated with the risk of exacerbations (Table 4). All 10 variables were included in a multivariable logistic regression as there were no correlations between the univariate predictors. The multivariable logistic regression model was statistically significant $\left(\chi^{2}=122.61\right.$, df $\left.=12, \mathrm{p}<0.001\right)$, accounting for $16.9 \%$ (Nagelkerke $\mathrm{R}$ squared) of the overall variance. As reported in Table 5, moderate-severe rhinitis was significantly associated with risk of asthma exacerbations $(\mathrm{OR}=1.40,95 \% \mathrm{CI}: 1.02-1.90)$. Other significant factors associated with exacerbation risk included: GINA-defined 


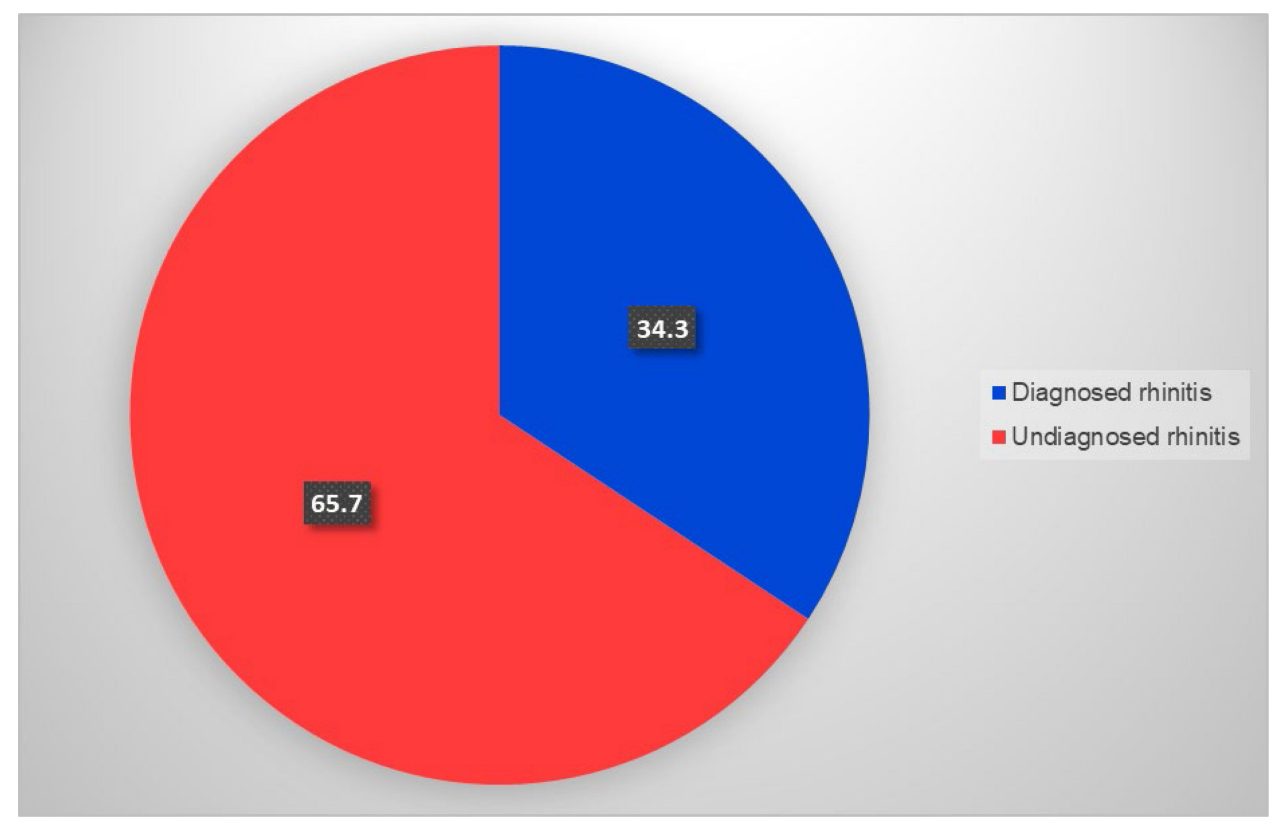

Figure I Incidence of diagnosed and undiagnosed rhinitis among patients reporting rhinitis symptoms $(\mathrm{N}=288 \mathrm{I})$.

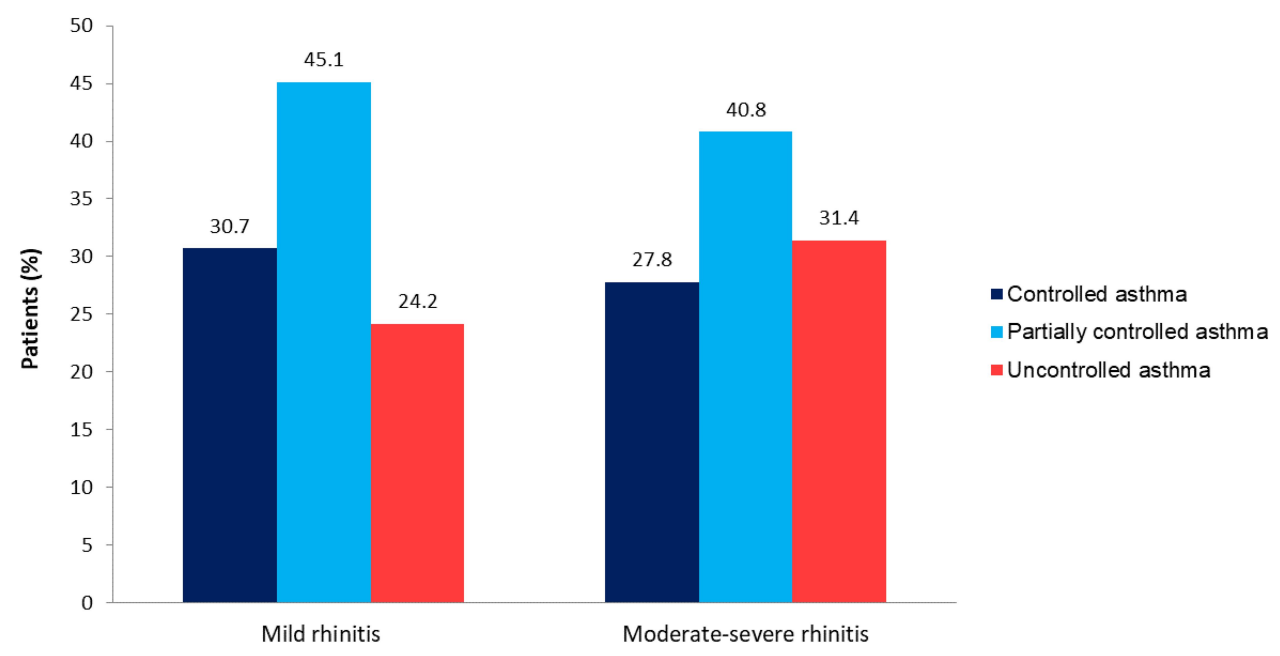

Figure 2 Asthma symptom control status in patients with mild $(\mathrm{N}=1829)$ and moderate-severe rhinitis $(\mathrm{N}=1052)$.

uncontrolled asthma ( $\mathrm{OR}=2.67,95 \% \mathrm{CI}: 1.76-4.04)$; not using preventer therapy every day $(\mathrm{OR}=1.96,95 \% \mathrm{CI}$ : 1.27-3.03); oropharyngeal effects while inhaling preventer treatment $(\mathrm{OR}=1.93,95 \%$ CI: $1.32-2.83)$; side-effects from preventer therapy $(\mathrm{OR}=1.82,95 \% \mathrm{CI}: 1.17-2.83)$; high-dose of SABA use (OR=1.83, 95\% CI: 1.18-2.82); diagnosis of GORD (OR=1.83, 95\% CI: 1.20-2.80); specialist review for asthma more than a year ago/never (vs previous year) $(\mathrm{OR}=1.77,95 \% \mathrm{CI}: 1.30-2.41)$ and obesity $(\mathrm{OR}=1.57,95 \%$ CI: 1.16-2.12). Smoking status was not associated with risk of exacerbations. There were two significant interactions: between GINA-defined asthma control and oropharyngeal effects; and between preventer adherence and side-effects (Table 5). The risk of exacerbations among patients with controlled/partially controlled asthma increased if they experienced oropharyngeal effects, and similarly among preventer medication adherers if they experienced side-effects.

\section{Discussion}

This research using the data from a large cross-sectional observational study investigated patient-reported rhinitis and its association with risk of asthma exacerbations in a large cohort of adults with asthma treated at GINA Step 3 
Table 2 Indicators of Asthma Symptoms and Exacerbations Overall and by Patient-Reported Rhinitis

\begin{tabular}{|c|c|c|c|c|}
\hline & \multirow[t]{2}{*}{ Overall $(N=4274)$} & \multicolumn{2}{|c|}{ Patient-Reported Rhinitis } & \multirow[t]{2}{*}{ p value* } \\
\hline & & No $(n=1393)$ & Yes $(n=288 I)$ & \\
\hline \multicolumn{5}{|l|}{ Asthma symptoms ${ }^{\mathrm{a}}$} \\
\hline \multicolumn{5}{|l|}{ Daytime symptoms, n (\%) } \\
\hline None & $2045(47.8)$ & $772(55.4)$ & $1273(44.2)$ & $<0.001^{\mathrm{b}}$ \\
\hline $\mathrm{I}-2$ days & $956(22.4)$ & $284(20.4)$ & $672(23.3)$ & \\
\hline$\geq 3$ days & $1273(29.8)$ & $337(24.2)$ & $936(32.5)$ & \\
\hline \multicolumn{5}{|l|}{ Activity limitations due to asthma, $n(\%)$} \\
\hline None & $3167(74.1)$ & $1109(79.6)$ & $2058(71.4)$ & $<0.001^{\mathrm{b}}$ \\
\hline$\geq 1$ day & $1107(25.9)$ & $284(20.4)$ & $823(28.6)$ & \\
\hline \multicolumn{5}{|l|}{ Night-time awakening, n (\%) } \\
\hline None & $3186(74.5)$ & $1150(82.6)$ & $2036(70.7)$ & $<0.001^{\mathrm{b}}$ \\
\hline$\geq 1$ day & $1088(25.5)$ & $243(17.4)$ & $845(29.3)$ & \\
\hline \multicolumn{5}{|l|}{ Reliever needed for symptoms, n (\%) } \\
\hline None & $2210(51.7)$ & $736(52.8)$ & $1474(5 \mid .2)$ & $0.6^{\mathrm{b}}$ \\
\hline $\mathrm{I}-2$ times & $733(17.2)$ & $230(16.5)$ & $503(17.5)$ & \\
\hline$\geq 3$ times & $|33|(3 \mid .1)$ & $427(30.7)$ & $904(31.4)$ & \\
\hline \multicolumn{5}{|l|}{ Highest number of puffs of reliever inhaler taken in I day ${ }^{\text {cd }}, \mathrm{n}(\%)$} \\
\hline $0-4$ & $3773(88.3)$ & $1260(90.5)$ & $25 \mid 3(87.2)$ & $0.002^{\mathrm{b}}$ \\
\hline $5-12$ or more & $501(11.7)$ & $133(9.5)$ & $368(12.8)$ & \\
\hline \multicolumn{5}{|l|}{ Acute exacerbations $\mathbf{s}^{\mathrm{e}}, \mathrm{n}(\%)$} \\
\hline \multicolumn{5}{|l|}{ Oral steroid use for worsening asthma } \\
\hline None & $2735(64.0)$ & $972(69.8)$ & $1763(61.2)$ & $<0.001^{\mathrm{b}}$ \\
\hline$\geq 1$ & $1539(36.0)$ & $421(30.2)$ & $1118(38.8)$ & \\
\hline \multicolumn{5}{|l|}{ Emergency department visit due to asthma } \\
\hline None & $3882(90.9)$ & $1286(92.4)$ & $2596(90.2)$ & $<0.001^{\mathrm{b}}$ \\
\hline$\geq 1$ visit & $389(9.1)$ & $106(7.6)$ & $283(9.8)$ & \\
\hline \multicolumn{5}{|l|}{ Hospitalisation due to asthma } \\
\hline None & $4090(95.7)$ & $1335(95.8)$ & $2755(95.7)$ & $0.8^{\mathrm{b}}$ \\
\hline$\geq$ I stay & $182(4.3)$ & $58(4.2)$ & $124(4.3)$ & \\
\hline \multicolumn{5}{|l|}{ Days absent from work/education due to asthma $(n=36 \mid 7)$} \\
\hline None & $3099(85.7)$ & $1113(90.0)$ & 1986 (83.4\%) & $<0.00 \mathrm{I}^{\mathrm{b}}$ \\
\hline$\geq$ I day & $5118(14.3)$ & $124(10.0)$ & 394 (16.6\%) & \\
\hline
\end{tabular}

Notes: $\mathrm{p}$ value* No rhinitis symptoms versus rhinitis symptoms. ${ }^{\mathrm{a}}$ In the 7 days before an iHARP asthma review. ${ }^{\mathrm{b}} \mathrm{p}$ value from chi-square test. ${ }^{\mathrm{c}}$ In the 4 weeks before an

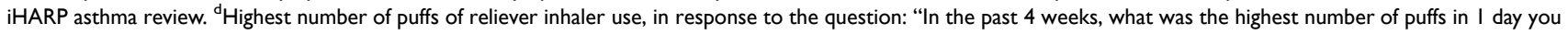
took of the reliever inhaler?" with response options I-4 puffs, 5-12 puffs and >12 puffs. 'In the 12 months before an iHARP asthma review.

and above who are managed in primary care. Our study revealed: (1) the prevalence of patient-reported rhinitis was higher than that of doctor-diagnosed rhinitis, with undiagnosed and/or poorly managed rhinitis highly prevalent in this cohort; (2) asthma patients with moderatesevere rhinitis were more likely to have GINA-defined uncontrolled asthma than those with mild rhinitis or no rhinitis and (3) moderate-severe rhinitis is associated with $40 \%$ increased risk of asthma exacerbations.
This cross-sectional observational analysis detected a major discrepancy between patient-reported and doctordiagnosed rhinitis using data collected from the iHARP asthma review, which would have been difficult to detect via other approaches such as general practice databases or medical records used in other studies. ${ }^{18-26}$ Our results showed that concomitant rhinitis is highly prevalent in patients who are considered to have moderate-severe asthma; however, the fact that rhinitis is likely to be 
Table 3 Clinical and Behavioural Characteristics Overall and by Patient-Reported Rhinitis

\begin{tabular}{|c|c|c|c|c|}
\hline & \multirow[t]{2}{*}{ Overall $(\mathrm{N}=4274)$} & \multicolumn{2}{|c|}{ Patient-Reported Rhinitis } & \multirow[t]{2}{*}{ p value* } \\
\hline & & No $(n=1393)$ & Yes $(n=288 I)$ & \\
\hline Patient-reported prior inhaler review by $\mathrm{HCP}^{\mathrm{a}}$, n (\%) & $2221(52.0)$ & $791(56.8)$ & $1430(49.7)$ & $0.009^{\mathrm{b}}$ \\
\hline Preventer adherence, $\mathrm{n}(\%)$ & $(n=3761)$ & $(n=1264)$ & $(n=2497)$ & \\
\hline Take it every day & $208 \mathrm{I}(55.3)$ & $805(63.7)$ & $1276(51.0)$ & $<0.001^{\mathrm{b}}$ \\
\hline Take it some days but others do not & $994(26.4)$ & $261(20.6)$ & $733(29.4)$ & \\
\hline Used to take it but now do not & $235(6.3)$ & $66(5.3)$ & $169(6.8)$ & \\
\hline Take it only when have symptoms & $214(5.7)$ & $75(5.9)$ & $139(5.6)$ & \\
\hline Never take it & $237(6.3)$ & $57(4.5)$ & $180(7.2)$ & \\
\hline \multicolumn{5}{|l|}{ Patient-reported side-effects ${ }^{c}, \mathrm{n}(\%)$} \\
\hline$\geq 1$ & I64| (38.4) & $459(33.0)$ & II $82(41.0)$ & $<0.00 \mathrm{I}^{\mathrm{b}}$ \\
\hline Patient-reported oropharyngeal effects ${ }^{d}, \mathrm{n}(\%)$ known & $(n=3755)$ & $(n=1264)$ & $(n=2491)$ & \\
\hline$\geq 1$ & $1833(48.6)$ & $472(37.3)$ & $|36|(54.6)$ & $<0.001^{b}$ \\
\hline \multicolumn{5}{|l|}{ Patient-reported specialist review, n (\%) } \\
\hline Never & $534(12.5)$ & $158(11.3)$ & $376(13.1)$ & $0.001^{\mathrm{b}}$ \\
\hline More than a year ago & $986(23.1)$ & $282(20.2)$ & $704(24.4)$ & \\
\hline In the past year & $2754(64.4)$ & $953(68.4)$ & $180 \mid(62.5)$ & \\
\hline
\end{tabular}

Notes: p value* No rhinitis symptoms versus rhinitis symptoms. ${ }^{a}$ In the previous 12 months. ${ }^{b} \mathrm{p}$ value from chi-square test. ${ }^{c}$ Patient-reported side-effects from preventer inhaler use, in response to the question: "Do you experience any of these side-effects from your preventer inhaler?" with "yes" or "no" responses for the following sideeffects: continual sore mouth/throat; oral thrush; bruising; hoarse voice; abnormal weight gain and cough. Patients could indicate more than one side-effect. 'Patientreported oropharyngeal effects during the inspiration phase of preventer inhaler use, in response to the question: When you use your preventer inhaler, do you feel a sensation at the back of your throat?; do you sometimes feel a need to cough?; do you feel your medication is deposited at the back of your throat? With yes' or "no" response options. Patients could indicate more than one oropharyngeal effect. In the 12 months before an iHARP asthma review.

Abbreviation: HCP, healthcare professional.

undiagnosed and/or poorly managed suggests that it may be more difficult for HCPs to diagnose rhinitis among patients with asthma, and/or is being overlooked by both patients and HCPs as a factor that can impair asthma control even with the most effective asthma therapy being prescribed. ${ }^{12,21,39,40,46}$ While asthma patients are known to underestimate the seriousness of their asthma, ${ }^{44}$ our findings suggest that they also underestimate the severity of their coexisting rhinitis, with only 1 in 3 adults indicating symptoms of moderate-severe rhinitis, which is inconsistent with their asthma severity, ${ }^{10}$, and rates reported in previous studies. ${ }^{19,20,47}$ This research is novel as it for the first time, takes a real-world/pragmatic approach to understand the relationship between rhinitis and asthma. Research to date has almost exclusively evaluated the impact of having doctor diagnosed AR on asthma exacerbations. ${ }^{24,25}$ The current research focused on patient-reported rhinitis. Therefore, our study enables

Table 4 Univariable Associations Between Patient Characteristics and Risk of Asthma Exacerbations

\begin{tabular}{|c|c|c|c|c|}
\hline & Reference Category & Category & Odds Ratio (95\% Cl) & $p$ value \\
\hline Body mass index & Underweight/normal weight & Obese & $1.31(1.13-1.53)$ & 0.001 \\
\hline Gastroesophageal diagnosis & No & Yes & $1.46(1.19-1.79)$ & $<0.001$ \\
\hline Smoking status & Never smoker & Current smoker & $1.74(1.44-2.09)$ & $<0.001$ \\
\hline GINA-defined asthma symptom control & Controlled/partially controlled & Uncontrolled & $1.40(1.22-1.61)$ & $<0.001$ \\
\hline Rhinitis severity & No & Moderate-severe & $1.74(1.47-2.05)$ & $<0.001$ \\
\hline Preventer adherence & Taken every day & Not taken every day & $2.42(2.10-2.78)$ & $<0.001$ \\
\hline Highest number of puffs of reliever taken in I day ${ }^{a}$ & $0-4$ & $5-12$ or more & $1.40(1.16-1.69)$ & $<0.001$ \\
\hline Oropharyngeal effects during inspiration phase & 0 & $\geq 1$ & $1.42(1.23-1.64)$ & $<0.001$ \\
\hline Side-effects from preventer inhaler use & 0 & $\geq 1$ & $0.62(0.54-0.70)$ & $<0.001$ \\
\hline Respiratory specialist review & In the previous year & More than a year ago/never & $0.71(0.62-0.8 I)$ & $<0.001$ \\
\hline
\end{tabular}

Note: ${ }^{a}$ In the 4 weeks before an iHARP asthma review.

Abbreviation: GINA, Global Initiative for Asthma. 
Table 5 Logistic Regression Predicting Likelihood of Asthma Exacerbations

\begin{tabular}{|c|c|c|c|c|c|}
\hline & Reference Category & Category & B & $\begin{array}{l}\text { Odds Ratio } \\
(95 \% \mathrm{Cl})\end{array}$ & $\begin{array}{l}\mathrm{P} \\
\text { value }\end{array}$ \\
\hline GINA-defined asthma symptom control & $\begin{array}{l}\text { Controlled/partially } \\
\text { controlled }\end{array}$ & Uncontrolled & 0.98 & $2.67(1.76-4.04)$ & $<0.001$ \\
\hline Preventer adherence & Taken every day & Not taken every day & 0.67 & $1.96(1.27-3.03)$ & 0.002 \\
\hline Oropharyngeal effects during inspiration phase & 0 & $\geq 1$ & 0.66 & $1.93(1.32-2.83)$ & 0.001 \\
\hline Gastroesophageal reflux disease & No & Yes & 0.61 & $1.83(1.20-2.79)$ & 0.005 \\
\hline Highest number of puffs of reliever taken in I day & $0-4$ & $5-12$ or more & 0.60 & $1.83(1.18-2.82)$ & 0.007 \\
\hline Side-effects from asthma therapy & 0 & $\geq 1$ & 0.60 & $1.82(1.17-2.83)$ & 0.008 \\
\hline Respiratory specialist review & In the previous year & $\begin{array}{l}\text { More than a year ago/ } \\
\text { never }\end{array}$ & 0.57 & $1.77(1.30-2.4 \mathrm{I})$ & $<0.001$ \\
\hline Body Mass Index & $\begin{array}{l}\text { Underweight/normal } \\
\text { weight }\end{array}$ & Obese & 0.45 & $1.57(1.16-2.12)$ & 0.003 \\
\hline Rhinitis severity & No & Moderate-severe & 0.33 & $1.40(1.02-1.90)$ & 0.036 \\
\hline Smoking status & Never smoker & Current smoker & 0.24 & $1.27(0.89-1.83)$ & 0.194 \\
\hline $\begin{array}{l}\text { GINA-defined asthma symptom control*Oropharyngeal } \\
\text { effects }\end{array}$ & $\begin{array}{l}\text { Controlled/partially } \\
\text { controlled } \\
0\end{array}$ & $\begin{array}{l}\text { Uncontrolled } \\
\geq 1\end{array}$ & -0.64 & $0.53(0.29-0.97)$ & 0.040 \\
\hline Preventer adherence*Side-effects from asthma therapy & $\begin{array}{l}\text { Not taken every day } \\
\geq 1\end{array}$ & $\begin{array}{l}\text { Taken every day } \\
0\end{array}$ & 0.59 & $1.80(1.01-3.25)$ & 0.049 \\
\hline
\end{tabular}

Notes: *Interaction with. ${ }^{\text {a }}$ n the 4 weeks before an iHARP asthma review.

Abbreviation: GINA, Global Initiative for Asthma.

us to identify potential confounding effects of undiagnosed or undocumented rhinitis in studies reporting on the impact of diagnosed rhinitis on asthma outcomes. This study uncovered the nature and extent of concomitant rhinitis in adults with asthma by using data collected via a structured asthma review approach, highlighting the need for such approaches to be an integral part of asthma consultations in primary care.

Our study indicated that rhinitis has a negative impact on asthma symptom control. This finding confirms previous reports showing a negative effect of rhinitis on the level of asthma control assessed by the Asthma Control Questionnaire among adult asthma patients with a diagnosis of rhinitis or documented allergen sensitisation, ${ }^{18-20}$ and that patients with moderate-severe rhinitis had the worst asthma control. ${ }^{17,48}$ In our study patients with rhinitis were less likely to use their preventer medication every day, yet were more likely to report side-effects from asthma therapy. While these findings seem contradictory, they may be explained by several factors: first, regular use of inhalers has shown to be associated with maintenance of correct inhaler technique (ie, practice makes perfect), thus irregular use of inhalers is associated with a deterioration in inhaler technique over time; ${ }^{49}$ second, patients reporting rhinitis in our study were less likely to have had their inhaler technique reviewed by a HCP in the past year - inhaler technique deteriorates over time and correct technique needs to be reinforced regularly, thus these patients are more likely to have poor inhaler technique; ${ }^{50}$ third, poor inhaler technique increases the risk of local side-effects such as dysphonia, ${ }^{51}$ and when side-effects occur, this reduces patient's willingness to use their inhalers regularly, which in turn becomes a vicious cycle, and fourth, since the majority of patients with rhinitis were not using optimal rhinitis therapy, our findings suggest that rhinitis with an inflamed mucosa might be a risk factor for local side-effects from preventer inhalers. This study also brings to light an interesting concept concerning the patient's ability to differentiate between coexisting upper and lower airway symptoms. Given that individually, worsening asthma symptoms and symptomatic episodes of rhinitis can cause night-time awakenings, breathlessness and cough, ${ }^{12,33}$ and impact on the ability to undertake activities, ${ }^{7,52}$ these findings question whether asthma patients are able to distinguish between asthma symptoms, asthma and rhinitis symptoms or just rhinitis symptoms alone when they respond to GINAdefined criteria/questions that are being asked for an objective evaluation of asthma control. These findings identify a gap in the management of rhinitis in general practice and the need for practitioners to identify, evaluate and optimally treat rhinitis in patients with asthma and better 
patient education concerning the link between rhinitis and asthma outcomes.

Interestingly, patients with suboptimal asthma control who reported rhinitis symptoms were more likely to accurately perceive that their asthma was "not well controlled" than patients with asthma alone. This finding suggests that these patients are more likely to voice their concerns and report troublesome asthma symptoms, search for asthmarelated information, education or care; this flags that while they recognise their asthma control is suboptimal, they may fail to recognise the coexistence of both chronic conditions, ${ }^{12}$ are unaware of the link between asthma and rhinitis, ${ }^{37}$ underestimate the magnitude of the impact of rhinitis on their daily lives $^{33,37,38}$ and often accept living with nasal symptoms, ${ }^{37,53}$ and hence, do not complain or volunteer to provide information about "trivial" nasal symptoms unless their physician asks. ${ }^{37,38}$ Primary care providers need to "prompt" patients by questioning them about the frequency, duration and impact of nasal symptoms on their daily lives when they are seeking asthma care. Our findings suggest the need to utilise simple validated assessment tools suitable for primary care, that capture both asthma and rhinitis symptom control, such as the Control of Allergic Rhinitis and Asthma Test (CARAT), which concurrently assesses symptoms of the upper and lower airways, sleep disturbances, limitation in normal activities and the need to adjust medication over a four-week period, ${ }^{54}$ or the MASK (Mobile Airways Sentinel Network)-air mobile phone application, which is specific for monitoring rhinitis in asthma and includes the CARAT. ${ }^{55}$

Importantly, this study found that moderate-severe rhinitis is associated with $40 \%$ increased risk of exacerbations among patients with asthma, despite GINA Step 3 and above maintenance therapy being prescribed. This finding emphasises the need to ensure that rhinitis symptoms are optimally controlled in patients dually affected by asthma and rhinitis. Optimal treatment of the upper airway may improve lower airway-specific symptoms, ${ }^{56,57}$ reduce the need for rescue medication, ${ }^{23,56}$ improve rates of controlled asthma and reduce future risk of adverse events. ${ }^{58}$ The finding that current smoking was not linked to increased risk of exacerbations in our study is inconsistent with previous reports among patients seen in general practice. ${ }^{17}$ A possible explanation for current smoking not to be statistically significant in the multivariable regression model may be due to a lack of power as only $12.9 \%$ of our patient cohort were current smokers. Two factors associated with exacerbation risk identified in our study, which have not been reported in the global strategy for asthma management, ${ }^{16}$ include side-effects of preventer therapy and oropharyngeal effects while inhaling preventer treatment. Risk of exacerbations doubled in patients experiencing side-effects and/or oropharyngeal effects from inhaled preventer medication; this risk increased even in patients with controlled/partially controlled asthma if they experienced oropharyngeal effects and in preventer medication adherers if they experienced side-effects. Oropharyngeal side-effects suggest poor inhaler technique which we know is related to poorer outcomes, such as poor asthma symptom control and increased risk of asthma exacerbations. ${ }^{51,59,60}$ Identification of the above three risk factors also suggests that these are potentially issues that could also be addressed by community pharmacy. Community pharmacists when dispensing asthma medication to people with asthma should check inhaler technique, adherence and oropharyngeal effects/side-effects of asthma medication, and recommend optimal rhinitis therapy, which, in some countries is available over-the-counter without prescription.

The strengths of the study include its large-scale size, observational design, evidence from real-life clinical practice and utilisation of a structured face-to-face asthma review approach that included objective and patientreported outcomes. Furthermore, this approach provided insight into patient behaviour such as inhaler technique that would have been difficult to capture via other approaches such as online surveys used in other studies. The study focused on those patients who had recent general practice contact who were prescribed combination preventer therapy (ie, GINA Step 3 and above); this being the most commonly used maintenance therapy for asthma at the time in primary care. There are several potential limitations to this study, which are related to the cross-sectional study design and a reliance on patient recall for self-reported exacerbations and medication taking behaviour, particularly with oral steroid use for asthma that may have been under- or over-stated by patients, or the confounding effect of oral steroid use for other conditions such as chronic rhinosinusitis. Other study limitations relate to patient recruitment over several countries, which may have led to greater variability in responses and the exclusion of patients with mild asthma (treated at GINA Step 1 or 2). While there were criteria to exclude patients with a diagnosis of chronic obstructive pulmonary disease (COPD) and given that most patients were 50 years of age or older with a past or current smoking history (and a greater risk of COPD), there is a possibility 
that patients with both asthma and COPD were included and could have biased the results. It is likely that most rhinitis identified in this study was indeed allergic in origin, but this cannot be confirmed due to the absence of data relating to the sensitisation status of the study population. Finally, while significant risk factors were identified, the overall variance accounted by the multivariable logistic regression model was low, suggesting other clinical, attitudinal or behavioural characteristics not regarded in the current analyses may relate to exacerbation risk and the need for further research in this area.

\section{Conclusion}

This study identified a major gap in the diagnosis and management of rhinitis in a cohort of people with asthma treated at GINA Step 3 and above who are managed in general practice. It highlights the need for practitioners to identify, evaluate and optimally treat rhinitis in adults with asthma, which is a significant factor associated with exacerbation risk.

\section{Data Sharing Statement}

The data that support the findings of this study are available from the corresponding upon reasonable request.

\section{Acknowledgments}

The iHARP database was funded by unrestricted grants from Mundipharma International Limited and Optimum Patient Care Global Ltd, which is a social enterprise that focuses on quality improvement in clinical practice. The sponsor was not involved in data analysis or the interpretation of the results.

\section{Author Contributions}

All authors made a significant contribution to the work reported, whether that is in the conception, study design, execution, acquisition of data, analysis and interpretation, or in all these areas; took part in drafting, revising or critically reviewing the article; gave final approval of the version to be published; have agreed on the journal to which the article has been submitted; and agree to be accountable for all aspects of the work.

\section{Disclosure}

V. Kritikos has received honoraria from AstraZeneca, GlaxoSmithKline and Pfizer, outside the submitted work. D. Price has board membership with Amgen, AstraZeneca, Boehringer Ingelheim, Chiesi, Circassia, Mylan, Mundipharma, Novartis, Regeneron Pharmaceuticals, Sanofi
Genzyme, Teva Pharmaceuticals, Thermofisher; consultancy agreements with Amgen, AstraZeneca, Boehringer Ingelheim, Chiesi, GlaxoSmithKline, Mylan, Mundipharma, Novartis, Pfizer, Teva Pharmaceuticals, Theravance; grants and unrestricted funding for investigator-initiated studies (conducted through Observational and Pragmatic Research Institute Pte Ltd) from AstraZeneca, Boehringer Ingelheim, Chiesi, Circassia, Mylan, Mundipharma, Novartis, Pfizer, Regeneron Pharmaceuticals, Respiratory Effectiveness Group, Sanofi Genzyme, Teva Pharmaceuticals, Theravance, UK National Health Service; payment for lectures/speaking engagements from AstraZeneca, Boehringer Ingelheim, Chiesi, Cipla, GlaxoSmithKline, Kyorin, Mylan, Mundipharma, Novartis, Regeneron Pharmaceuticals, Sanofi Genzyme, Teva Pharmaceuticals; payment for the development of educational materials from Mundipharma, Novartis; payment for travel/ accommodation/meeting expenses from AstraZeneca, Boehringer Ingelheim, Mundipharma, Mylan, Novartis, Thermofisher; funding for patient enrolment or completion of research from Novartis; stock/stock options from AKL Research and Development Ltd which produces phytopharmaceuticals; owns $74 \%$ of the social enterprise Optimum Patient Care Ltd (Australia and UK) and 74\% of Observational and Pragmatic Research Institute Pte Ltd (Singapore); 5\% shareholding in Timestamp which develops adherence monitoring technology; is peer reviewer for grant committees of the Efficacy and Mechanism Evaluation programme and Health Technology Assessment; and was an expert witness for GlaxoSmithKline. A. Papi is on the boards for and has received research and travel support and consultancy and lecture fees from Chiesi Farmaceutici, AstraZeneca, GlaxoSmithKline, Boehringer Ingelheim, Merck Sharp \& Dohme, Takeda, Mundipharma Research Limited, and Teva; has received lecture fees and travel support from Menarini, Novartis, and Zambon; is on the boards for and has received lecture fees and travel support from Pfizer, and has received research support from Sanofi. B. Ställberg has received honoraria for educational activities and lectures from AstraZeneca, Boehringer Ingelheim, Chiesi, Novartis, Meda, Novartis and Teva, and has served on advisory boards arranged by GlaxoSmithKline, AstraZeneca, Novartis, Meda, and Boehringer Ingelheim. D. Ryan has received speaker fees from Mylan, AstraZeneca, Chiesi; received consultancy fees from GlaxoSmithKline, Novartis, AstraZeneca, Boehringer Ingelheim, and for educational activities from Regeneron and Medspace in the last three years. He is the Vice President of Respiratory Effectiveness Group (REG) and the Consultant 
Clinical Strategic Director of Optimum Patient Care (OPC). F. Lavorini has received honoraria for consultancy and presentations from Cipla, Almirall, AstraZeneca, Boehringer Ingelheim, Chiesi, GSK, HIKMA, Menarini International, Mundipharma, Orion, Teva, Trudell International, and Zentiva. H. Chrystyn has no shares in any pharmaceutical companies; is employed by RiRL, which is subcontracted by Observational and Pragmatic Research Institute Pte Ltd; has received sponsorship to carry out studies, together with board membership, consultancy agreements, and honoraria for presentation for Almirall, AstraZeneca, Boehringer Ingelheim, Chiesi, GlaxoSmithKline, Innovata, Biomed, Meda, Napp Pharmaceuticals, Mundipharma Research Limited, NorPharma, Novartis, Orion, Sanofi, Teva, Truddell Medical International, UCB and Zentiva; and owns 50\% of Inhalation Consultancy Ltd. J. Haughney has received reimbursements for attending symposia, fees for speaking, organizing educational events, funds for research, or fees for consulting from Cipla, Chiesi, AstraZeneca, Boehringer Ingelheim, GlaxoSmithKline, Merck Sharpe \& Dohme, Mundipharma Research Limited, Novartis and Teva. K. Lisspers has received payments for educational activities and lectures from AstraZeneca, Novartis, Boehringer Ingelheim, Chiesi and TEVA and fees for advisory boards from AstraZeneca, Boehringer Ingelheim, GlaxoSmithKline and for scientific steering committee from Novartis. K. Gruffydd-Jones declares speaking engagements and consultancy for AstraZeneca, GlaxoSmithKline, Boehringer Ingelheim, Mundipharma, Napp Pharma, and Novartis. M. Román-Rodríguez has received personal fees from Almirall, AstraZeneca, GlaxoSmithKline, Boehringer Ingelheim, Chiesi, Menarini, Mundipharma Research Limited, Novartis, Pfizer, Rovi, Teva, Trudell, and Gebro and has received research support from personal fees from GlaxoSmithKline. T. van der Molen was an employee of GSK between 2017 and 2019. V. Carter is an employee of Optimum Patient Care Ltd and Observational and Pragmatic Research Institute Pte Ltd. S. BosnicAnticevich has received payment for lectures, expert advice, and independent research from Teva, AstraZeneca, Boehringer Ingelheim, GlaxoSmithKline, Meda, Mundipharma, Mylan and Sanofi, outside the submitted work. The authors report no other conflicts of interest in this work.

\section{References}

1. Global Asthma Network (GAN). The Global Asthma Report; 2018. Available from: http://www.globalasthmareport.org/Global\% 20Asthma\%20Report\%202018.pdf. Accessed May 16, 2020.
2. Pawankar R, Canonica G, Holgate S, Loceky R World Allergy Organisation (WAO). White Book on Allergy. Wisconsin: world Allergy Organisation; 2020. Available from: https://www.worldallergy. org/UserFiles/file/WhiteBook2-2013-v8.pdf. Accessed May 16, 2020.

3. European Lung white book. 2018. Available from: https://www.ers whitebook.org/chapters. Accessed May 16, 2020.

4. Bousquet J, Khaltaev N, Cruz AA, et al. Allergic Rhinitis and its Impact on Asthma (ARIA) 2008 update (in collaboration with the World Health Organization, GA(2)LEN and AllerGen). Allergy. 2008;63(Suppl 86):8-160.

5. Bousquet PJ, Demoly P, Devillier P, Mesbah K, Bousquet J. Impact of allergic rhinitis symptoms on quality of life in primary care. Int Arch Allergy Immunol. 2013;160(4):393-400.

6. Small M, Piercy J, Demoly P, Marsden H. Burden of illness and quality of life in patients being treated for seasonal allergic rhinitis: a cohort survey. Clin Transl Allergy. 2013;3:33.

7. Valovita E, Myrseth SE, Palkonen S. The voice of the patients: allergic rhinitis is not a trivial disease. Curr Opin Allergy Clin Immunol. 2008;8:1-9.

8. Canonica GW, Bousquet J, Mullol J, Scadding GK, Virchow JC. A survey of the burden of allergic rhinitis in Europe. Allergy. 2007;62:17-25.

9. Meltzer EO, Bukstein DA. The economic impact of allergic rhinitis and current guidelines for treatment. Ann Allergy Asthma Immunol. 2011;106(Suppl 2):12-16.

10. Togias A. Rhinitis and asthma: evidence for respiratory system integration. $J$ Allergy Clin Immunol. 2003;111(6):1171-1183. doi:10.1067/mai.2003.1592

11. Brożek JL, Bousquet J, Agache I, et al. Allergic Rhinitis and its Impact on Asthma (ARIA) guidelines-2016 revision. J Allergy Clin Immunol. 2017;140(4):950-958. doi:10.1016/j.jaci.2017.03.050

12. Scadding G, Walker S. Poor asthma control? - then look up the nose. The importance of co-morbid rhinitis in patients with asthma. Prim Care Respir J. 2012;21(2):222-228. doi:10.4104/pcrj.2012.00035

13. Thomas M. Allergic rhinitis: evidence for impact on asthma. $B M C$ Pulm Med. 2006;6(1):S4. doi:10.1186/1471-2466-6-S1-S4

14. Shaaban R, Zureik M, Soussan D, et al. Rhinitis and onset of asthma: a longitudinal population-based study. The Lancet. 2008;372 (9643):1049-1057. doi:10.1016/S0140-6736(08)61446-4

15. Burgess JA, Walters EH, Byrnes GB, et al. Childhood allergic rhinitis predicts asthma incidence and persistence to middle age: a longitudinal study. J Allergy Clin Immunol. 2007;120(4):863-869. doi:10.1016/j.jaci.2007.07.020

16. Global Initiative for Asthma. Global Strategy for Asthma Management and Prevention. 2020. Available from: www. ginasthma.org. Accessed May 16, 2020.

17. Clatworthy J, Price D, Ryan D, Haughney J, Horne R. The value of self-report assessment of adherence, rhinitis and smoking in relation to asthma control. Prim Care Respir J. 2009;18(4):300-305. doi:10.4104/pcrj.2009.00037

18. Maio S, Baldacci S, Simoni M, et al. Impact of asthma and comorbid allergic rhinitis on quality of life and control in patients of Italian general practitioners. J Asthma. 2012;49(8):854-861.

19. Vandenplas O, Dramaix M, Joos G, et al. The impact of concomitant rhinitis on asthma-related quality of life and asthma control. Allergy. 2010;65(10):1290-1297. doi:10.1111/j.1398-9995.2010.02365.x

20. Magnan A, Meunier JP, Saugnac C, Gasteau J, Neukirch F. Original article: frequency and impact of allergic rhinitis in asthma patients in everyday general medical practice: a French observational cross-sectional study. Allergy. 2007;63(3):292-298. doi:10.1111/j.13989995.2007.01584.x

21. Braido F, Baiardini I, Brandi S, Porcu A, Canonica GW. Allergic rhinitis and asthma ad hoc survey: clinical and psychological perspectives. Clin Exp Allergy. 2007;37(5):788-793. doi:10.1111/j.13652222.2007.02702.x 
22. Leynaert B, Neukirch C, Liard R, Bousquet J, Neukirch F. Quality of life in allergic rhinitis and asthma: a population-based study of young adults. Am J Respir Crit Care Med. 2000;162(4):1391-1396. doi:10.1164/ajrccm.162.4.9912033

23. Gaugris S, Sazonov-Kocevar V, Thomas M. Burden of concomitant allergic rhinitis in adults with asthma. $J$ Asthma. 2006;43(1):1-7. doi:10.1080/02770900500446823

24. Price D, Zhang Q, Kocevar VS, Yin DD, Thomas M. Effect of a concomitant diagnosis of allergic rhinitis on asthma-related health care use by adults. Clin Exp Allergy. 2005;35(3):282-287. doi:10.1111/j.1365-2222.2005.02182.x

25. Brandão HV, Cruz CS, Pinheiro $\mathrm{MC}$, et al. Fatores de risco para visitas à emergência por exacerbações de asma em pacientes de um programa de controle da asma e rinite alérgica em Feira de Santana, BA. J Brasileiro De Pneumologia. 2009;35(12):1168-1173. doi:10.1590/S1806-37132009001200002

26. Singh U, Wangia-Anderson V, Bernstein JA. Chronic rhinitis is a highrisk comorbidity for 30-day hospital readmission of patients with asthma and chronic obstructive pulmonary disease. J Allergy Clin Immunol Pract. 2019;7(1):279-285. doi:10.1016/j.jaip.2018.06.029

27. Baiardini I, Braido F, Bonini M, Compalati E, Canonica GW. Why do doctors and patients not follow guidelines? Curr Opin Allergy Clin Immunol. 2009;9(3):228-233. doi:10.1097/ACI.0b013e32832b4651

28. Ryan D, Grant-Casey J, Scadding G, Pereira S, Pinnock H, Sheikh A. Management of allergic rhinitis in UK primary care: baseline audit. Prim Care Respir J. 2005;14(4):204-209. doi:10.1016/j.pcrj.2005.03.009

29. Costa DJ, Bousquetbh PJ, Ryan D, et al. Guidelines for allergic rhinitis need to be used in primary care. Prim Care Respir J. 2009;18(4):250-257. doi:10.4104/pcrj.2009.00028

30. Ciprandi G, Cirillo I. Monosensitization and polysensitization in allergic rhinitis. Eur J Intern Med. 2011;22(6):e75-e79. doi:10.1016/j.ejim.2011.05.009

31. Settipane RA. Demographics and epidemiology of allergic and nonallergic rhinitis. Allergy and Asthma Proc. 2001;22:185-189.

32. Bousquet PJ, Bachert C, Canonica GW, et al. Uncontrolled allergic rhinitis during treatment and its impact on quality of life: A cluster randomized trial. J Allergy Clin Immunol. 2010;126(3):666-668. doi:10.1016/j.jaci.2010.06.034

33. Seedat RY. Allergic rhinitis-more than just a nuisance. Curr Allergy Clin Immunol. 2013;26(1):8-9.

34. Fromer LM, Blaiss MS, Jacob-Nara JA, Long RM, Mannion KM, Lauersen LA. Current Allergic Rhinitis Experiences Survey (CARES): consumers' awareness, attitudes and practices. Allergy Asthma Proc. 2014;35(4):4. doi:10.2500/aap.2014.35.3766

35. Mehuys E, Gevaert P, Brusselle G, et al. Self-medication in persistent rhinitis: overuse of decongestants in half of the patients. J Allergy Clin Immunol Pract. 2014;2(3):313-319. doi:10.1016/j.jaip.2014.01.009

36. Maurer M, Zuberbier T. Undertreatment of rhinitis symptoms in Europe: findings from a cross-sectional questionnaire survey. Allergy. 2007;62(9):1057-1063. doi:10.1111/j.1398-9995.2007.01367.x

37. Nolte H, Nepper-Christensen S, Backer V. Unawareness and undertreatment of asthma and allergic rhinitis in a general population. Respir Med. 2006;100(2):354-362. doi:10.1016/j.rmed.2005.05.012

38. Small P, Keith PK, Kim H. Allergic rhinitis. Allergy Asthma Clin Immunol. 2018;14(2):51.

39. Gillis RM, van Litsenburg W, van Balkom RH, Muris JW, Smeenk FW. The contribution of an asthma diagnostic consultation service in obtaining an accurate asthma diagnosis for primary care patients: results of a real-life study. Npj Primary Care Respiratory Medicine. 2017;27(1):1-5. doi:10.1038/s41533-017-0027-9

40. Bauchau V. Prevalence and rate of diagnosis of allergic rhinitis in Europe. Eur Respir J. 2004;24(5):758-764. doi:10.1183/ 09031936.04.00013904

41. iHARP database [homepage on the Internet]. 2018. Available from: https://opcrd.co.uk/international-helping-asthma-in-real-life-patientsiharp/. Accessed May 16, 2020.
42. Price D, Bond $\mathrm{C}$, Bouchard $\mathrm{J}$, et al. International Primary Care Respiratory Group (IPCRG) Guidelines: management of allergic rhinitis. Prim Care Respir J. 2006;15(1):58-70. doi:10.1016/j.pcrj.2005.11.002

43. Global Initiative for Asthma. Global Strategy for Asthma Management and Prevention (Revised 2010). Available from: www. ginasthma.org. Accessed August 14, 2011.

44. Price D, Fletcher M, van der Molen T. Van Der Molen T. Asthma control and management in 8000 European patients: the REcognise Asthma and LInk to Symptoms and Experience (REALISE) survey. Npj Primary Care Respiratory Medicine. 2014;24(1):14009. doi:10.1038/npjpcrm.2014.9

45. Price D, David-Wang A, Cho SH, et al. Time for a new language for asthma control: results from REALISE Asia. J Asthma Allergy. 2015;8:93.

46. Oka A, Matsunaga K, Kamei $\mathrm{T}$, et al. Ongoing allergic rhinitis impairs asthma control by enhancing the lower airway inflammation. J Allergy Clin Immunol Pract. 2014;2(2):172-178. doi:10.1016/j. jaip.2013.09.018

47. Walker $\mathrm{S}$, Sheikh A. Self reported rhinitis is a significant problem for patients with asthma. Prim Care Respir J. 2005;14(2):83-87. doi:10.1016/j.pcrj.2004.10.005

48. Bosnic-Anticevich S, Kritikos V, Carter V, et al. Lack of asthma and rhinitis control in general practitioner-managed patients prescribed fixed-dose combination therapy in Australia. J Asthma. 2006;6 (S1):684-694. doi:10.1080/02770903.2017.1353611

49. Azzi E, Srour P, Armour C, Rand C, Bosnic-Anticevich S. Practice makes perfect: self-reported adherence a positive marker of inhaler technique maintenance. Npj Prim Care Respir Med. 2017;27(1):1-6.

50. Lavorini F, Magnan A, Dubus JC, et al. Effect of incorrect use of dry powder inhalers on management of patients with asthma and COPD. Respir Med. 2008;102(4):593-604.

51. Levy ML, Dekhuijzen PN, Barnes PJ, et al. Inhaler technique: facts and fantasies. A view from the Aerosol Drug Management Improvement Team (ADMIT). Npj Prim Care Respir Med. 2016;26(1):1-7.

52. Price D, Scadding G, Ryan D, et al. The hidden burden of adult allergic rhinitis: UK healthcare resource utilisation survey. Clin Transl Allergy. 2015;5(1):39.

53. Price D, Smith P, Hellings $P$, et al. Current controversies and challenges in allergic rhinitis management. Exp Rev Clin Immunol. 2015;11(11):1205-1217.

54. Azevedo P, Correia-de-Sousa J, Bousquet J, et al. Control of Allergic Rhinitis and Asthma Test (CARAT): dissemination and applications in primary care. Prim Care Respir J. 2013;22(1):112-116.

55. Bousquet J, Arnavielhe S, Bedbrook A, et al. MASK 2017: ARIA digitally-enabled, integrated, person-centred care for rhinitis and asthma multimorbidity using real-world-evidence. Clin Transl Allergy. 2018;8(1):1-21.

56. Lohia S, Schlosser RJ, Soler ZM. Impact of intranasal corticosteroids on asthma outcomes in allergic rhinitis: a meta-analysis. Allergy. 2013;68(5):569-579.

57. Aubier M, Levy J, Clerici C, Neukirch F, Herman D. Different effects of nasal and bronchial glucocorticosteroid administration on bronchial hyperresponsiveness in patients with allergic rhinitis. Am Rev Respir Disease. 1992;146(1):122-126.

58. Crystal-Peters J, Neslusan C, Crown WH, Torres A. Treating allergic rhinitis in patients with comorbid asthma: the risk of asthma-related hospitalizations and emergency department visits. J Allergy Clin Immunol. 2002;109(1):57-62.

59. Melani AS, Bonavia M, Cilenti $\mathrm{V}$, et al. Inhaler mishandling remains common in real life and is associated with reduced disease control. Respir Med. 2011;105(6):930-938.

60. Price DB, Román-Rodríguez M, McQueen RB, et al. Inhaler errors in the CRITIKAL study: type, frequency, and association with asthma outcomes. $J$ Allergy Clin Immunol Pract. 2017;5 (4):1071-1081. 


\section{Publish your work in this journal}

The Journal of Asthma and Allergy is an international, peer-reviewed open-access journal publishing original research, reports, editorials and commentaries on the following topics: Asthma; Pulmonary physiology; Asthma related clinical health; Clinical immunology and the immunological basis of disease; Pharmacological interventions and new therapies. The manuscript management system is completely online and includes a very quick and fair peer-review system, which is all easy to use. Visit http://www.dovepress.com/testimonials.php to read real quotes from published authors. 